\title{
Research on certified reference material of benzene in toluene
}

\author{
Yuebing Sha ${ }^{\mathrm{a}}$, Xiaobo $\mathrm{Yu}^{\mathrm{b}}, \mathrm{Ke} \mathrm{Wang}^{\mathrm{c}}$
}

\author{
Chemistry and Environment Metrology Department, Zhejiang Institute of Metrology, 300Xiasha \\ Road, China 310018 \\ ashaybing@163.com, byuxiaobo.123@163.com, ${ }^{\mathrm{C}}$ akeguozi@163.com
}

Keywords: benzene; certified reference material; uniformity; stability; uncertainty evaluation

\begin{abstract}
The verification certified reference material about thermal conductivity detector (TCD) of gas chromatograph was studied and the preparation was introduced. This article in detail introduced uniformity, stability assessment of certified reference material and analyzed the uncertainty evaluation. The result was up to the requirement of JJG 700-1999 Verification Regulation of gas chromatograph.
\end{abstract}

\section{Introduction}

Huge numbers of GC analytical instruments were used in food, environmental protection and chemical engineering. The traceability of value of a quantity of certified reference material (CRM) of benzene in toluene about TCD-JJG 700-1999 Verification Regulation of gas chromatograph was widely used in measure system. The article put forwards on the study of CRM of benzene in toluene, raw material-selecting, the measurement method of characteristic value, the preparation, uniformity, stability and fixed value of CRM. The intercomparison of reference material were certified by National Institute of Metrology laboratory, which indicating reference material with good performance could be used as quantity transmission, evaluation on calibration and verification of TCD analysis and quality control .

\section{(1)Reagents and devices}

1)Benzene: GBW06104a, Tianjin Institute of Measurement Technology,purity:99.91\%, relative uncertainty: $\pm 0.03 \%$.

2)Toluene: TEDIA,USA, purity:99.8\%.

3)Electronic balance:Sartorius,25mg, $0.01 \mathrm{mg}$.

4) $250 \mathrm{~mL}$ volumetric flask.

\section{(2)Preparation}

The concentration of standard solution was $5.00 \mathrm{mg} / \mathrm{mL}$ through precisely weighing $1251 \mathrm{mg}$ benzene on the electronic balance under the $20^{\circ} \mathrm{C} \pm 4^{\circ} \mathrm{C}$ condition. The constant volume was $250 \mathrm{~mL}$ with toluene and mixed completely.

\section{Homogeneity examination of standard solution}

\section{(1)Homogeneity examination}

Shake up the standard solution could eliminate in homogeneity of within-bottle ${ }^{[1]}$.According to ISO Guide35, uniformity of the reference material was evaluated by uncertainty of in homogeneity and variance analysis was used to verify homogeneity.

If the statistical test of data had no significant difference under repeatability condition, statistics less than critical value $\left(\mathrm{F}_{\mathrm{s}}<\mathrm{F}_{\mathrm{c}}\right)$, the distribution of characteristic values measured in the sample was homogeneous.

\section{(2)Process of homogeneity examination}

Instruments: gas chromatograph Agilent7890, US13231022.Conditions: column:HP-5 5\% (Agilent), $\quad 30 \mathrm{~m} \times 0.32 \mathrm{~mm} \times 0.25 \mu \mathrm{m}$,injection volume: $1 \mu \mathrm{L}$,split ratio: $10: 1$, injector: $120{ }^{\circ} \mathrm{C}$,column flow: $1.5 \mathrm{~mL} / \mathrm{min}$, oven: $45^{\circ} \mathrm{C}$, keep 10 minutes; detector: $160^{\circ} \mathrm{C}$.

15 bottles were randomly selected from 200 bottles which were used to test of homogeneity and 
compared with GBW(E)130101.

(3)The result of homogeneity examination

The result was listed in table 1.

Table 1 homogeneity data of benzene in toluene $(\mathrm{mg} / \mathrm{mL})$

\begin{tabular}{ccccc}
\hline No. & 1 & 2 & 3 & 4 \\
\hline 1 & 4.98 & 4.98 & 5.01 & 4.98 \\
2 & 4.96 & 4.97 & 5.02 & 5.00 \\
3 & 5.00 & 4.99 & 5.05 & 5.04 \\
4 & 4.97 & 4.97 & 5.00 & 5.01 \\
5 & 5.04 & 4.98 & 5.01 & 4.97 \\
6 & 4.98 & 5.03 & 5.10 & 5.00 \\
7 & 4.93 & 5.02 & 5.01 & 4.97 \\
8 & 5.02 & 5.02 & 4.98 & 5.01 \\
9 & 5.01 & 4.99 & 4.99 & 5.02 \\
10 & 5.03 & 5.04 & 5.07 & 5.02 \\
11 & 5.03 & 4.97 & 5.02 & 4.90 \\
12 & 4.92 & 4.94 & 4.98 & 5.00 \\
13 & 5.02 & 5.02 & 4.99 & 5.03 \\
14 & 4.99 & 4.99 & 5.04 & 5.00 \\
15 & 5.00 & 5.01 & 5.04 & 5.01 \\
\hline
\end{tabular}

$\mathrm{F}(14,45)=1.75<\mathrm{F}_{0.05}(14,45)=1.91$

The certified reference material of benzene in toluene was homogeneity and the uncertainty of homogeneity was added to total uncertainty.

\section{Stability examination of standard solution}

(1) The method of stability examination

In different time, the relationship between time and value was described to evaluate stability.

Uncertainty about intercept:

$$
s\left(b_{1}\right)=\frac{s}{\sqrt{\sum_{i=1}^{n}(X i-\bar{X})^{2}}}
$$

If $\left|b_{1}\right|<t_{0.95, n-2} * s\left(b_{1}\right)$, intercept was inconspicuousness, having no instability.

(2) Process of stability examination

According to certified reference material technical principle of higher efficiency and lower resistance, stability of benzene in toluene was examined ${ }^{[2]}$.Under the same experiment and homogeneity examination condition, each randomly selected a sample and each sample was measured four times in parallel, using certified reference material (GBW (E) 130101, $5.00 \mathrm{mg} / \mathrm{mL}$ ) to compare measurements at different time intervals.

(3) The result of stability examination

The result was listed in table 2 . 
Table 2 the stability data of benzene in toluene $(5.00 \mathrm{mg} / \mathrm{mL})$

\begin{tabular}{cccccc}
\hline experiment time/month & 1 & 2 & 3 & 4 & average \\
\hline 1 & 5.03 & 5.00 & 5.25 & 4.85 & 5.03 \\
2 & 4.99 & 4.98 & 5.22 & 5.29 & 5.12 \\
3 & 5.03 & 4.96 & 5.21 & 5.22 & 5.10 \\
4 & 5.04 & 5.01 & 5.11 & 5.11 & 5.07 \\
6 & 5.03 & 4.98 & 5.03 & 5.10 & 5.03 \\
9 & 4.82 & 5.02 & 5.05 & 5.09 & 5.00 \\
12 & 5.04 & 5.05 & 5.05 & 5.06 & 5.05 \\
\hline
\end{tabular}

The stability evaluation on the regression variance analysis method was used to check fitting curve with data that the $\mathrm{X} \mathrm{Y}$ (time versus concentrate) relation. The result of variance analysis was listed in table 3.

Table 3 analysis of stability results of benzene in toluene

\begin{tabular}{lcccccccc}
\hline & & & & & & & & \\
& Coefficients & $\begin{array}{c}\text { standard } \\
\text { deviation }\end{array}$ & t Stat & P-value & $\begin{array}{c}\text { Lower } \\
95 \%\end{array}$ & $\begin{array}{c}\text { Upper } \\
95 \%\end{array}$ & $\begin{array}{c}\text { lower } \\
\text { limit } \\
95.0 \%\end{array}$ & $\begin{array}{c}\text { upper } \\
\text { limit } \\
95.0 \%\end{array}$ \\
\hline Intercept & 5.088018 & 0.026929 & 188.9394 & $7.88 \mathrm{E}-11$ & 5.018794 & 5.157242 & 5.018794 & 5.157242 \\
$\mathrm{X}$ Variable 1 & -0.00567 & 0.004177 & -1.35765 & 0.232632 & -0.01641 & 0.005066 & -0.01641 & 0.005066 \\
\hline
\end{tabular}

$\mathrm{df}=\mathrm{n}$-2(degree of freedom), $\mathrm{p}=0.95$ and $\mathrm{t}=2.23$. Due to $\left|b_{1}\right|<t_{0.95, n-2} * s\left(b_{1}\right)$, the value of standard solution having no obvious change showed us the storage condition was efficient.

\section{Fixed value of standard solution ${ }^{[3]}$}

The standard solution was prepared by weight-capacity.

$$
c_{\text {benzene }}=\frac{m_{\text {benzene }} p_{\text {benzene }}}{V}=\frac{1251 \times 99.91 \%}{250}=5.00 \mathrm{mg} / \mathrm{mL}
$$

$C$ benzene : mass concentration of benzene, $\mathrm{mg} / \mathrm{mL}$. $m$ benzene : mass of benzene reagents.

$p$ benzene :purity of benzene. V: $250 \mathrm{~mL}$ volumetric flask.

\section{Uncertainty evaluation and results expression ${ }^{[4]}$}

\section{(1)Uncertainty components}

The uncertainty components were in table 4 .

Table 4 uncertainty components of benzene in toluene

\begin{tabular}{|c|c|c|c|c|c|c|c|}
\hline \multirow{2}{*}{$\begin{array}{l}\text { uncertainty } \\
\text { components }\end{array}$} & \multirow{2}{*}{$\begin{array}{c}\text { purity of } \\
\text { benzene } \\
u_{\text {rel,1 }}\end{array}$} & \multicolumn{2}{|c|}{ electronic balance } & \multicolumn{2}{|c|}{ volumetric flask } & \multirow{2}{*}{$\begin{array}{c}\text { homogeneity } \\
u_{\mathrm{rel}, 6} \\
\end{array}$} & \multirow{2}{*}{$\begin{array}{c}\text { stability } \\
u_{\text {rel }, 7}\end{array}$} \\
\hline & & $u_{\mathrm{rel}, 2}$ & $u_{\mathrm{rel}, 3}$ & $u_{\mathrm{rel}, 4}$ & $u_{\text {rel }, 5}$ & & \\
\hline value & $0.03 \%$ & $0.01 \%$ & $0.01 \%$ & $0.02 \%$ & $0.25 \%$ & $0.27 \%$ & $1.00 \%$ \\
\hline
\end{tabular}


(2)Expanded uncertainty ${ }^{[5]}$

combined uncertainty

$$
u_{\text {rel, benzene }}=\sqrt{u_{\text {rel, }, 1}^{2}+u_{\text {rel, }, 2}^{2}+u_{\text {rel, }, 3}^{2}+u_{\text {rel, }, 4}^{2}+u_{\text {rel, } 5}^{2}+u_{\text {rel, } 6}^{2}+u_{\text {rel, }, 7}^{2}}=1.1 \%
$$

expanded uncertainty

$$
U_{\text {rel, } \text {,епесе }}=k \times u_{\text {rel, } \text {,епеzе }}=2 \times 1.1 \%=3 \% \quad k=2
$$

\section{(3) Results expression}

The value of benzene in toluene was $5.00 \mathrm{mg} / \mathrm{mL}, \quad U_{\text {rel }}=3 \%, k=2$

\section{Conclusions}

The trial result of the standard solution indicting the uncertainty, uniformity and stability of the value results met the requirements of JJG700-1999 gas chromatograph, so the CRM could be used as TCD measurement standard substances.

Author introduction: ShaYuebing (1980- ), male, senior engineer, Working Department: Measurement Science Research Institute of Zhejiang province, Address: Hangzhou City, Zhejiang province Xiasha Road No. 300 Building No. 1.

Research Direction: Stoichiometry.

\section{References}

[1]International Organization for Standardization (ISO), Guide 35-2006, Reference materials-General and statistical principles for certification [S].

[2] JJF1006-1994 Technical Norm of Primary Reference Material [S].

[3] JJF 1343-2012 General and Statistical Principles for Characterization of Reference Materials [S].

[4] JJF 1059.1-2012 Evaluation and Expression of Uncertainty in Measurement[S].

[5] CNAS CL07-2011, Requirements for Measurement Uncertainty[S]. 